\title{
O ESTUDO DA RELAÇÃO TERNÁRIA PARA O ENSINO DO CAMPO CONCEITUAL MULTIPLICATIVO
}

\author{
EL ESTUDIO DE LA RELACIÓN TERNARIA PARA LA ENSEÑANZA \\ DEL CAMPO CONCEPTUAL MULTIPLICATIVO
}

\begin{abstract}
THE STUDY OF THE TERNARY RELATIONSHIP FOR THE TEACHING OF THE MULTIPLICATIVE CONCEPTUAL FIELD
\end{abstract}

DOI: $10.22481 /$ rbba.v10i01.8319

Maria Elizabete Souza Couto Universidade Estadual de Santa Cruz, Ilhéus, Bahia, Brasil

ID Lattes: http://lattes.cnpq.br/1085573737741686

ORCID: http://orcid.org/0000 - 0002 - 0026 - 5266

Endereço eletrônico: mcouto@uesc.br

Débora Cabral Lima Centro Integrado Cristo Redentor, Ilhéus, Bahia, Brasil

ID Lattes: http://lattes.cnpq.br/7788242512061173

ORCID: http://orcid.org/0000-0002-9999-7407

Endereço eletrônico: cabraldebora@yahoo.com.br

Eurivalda Ribeiro dos Santos Santana Universidade Estadual de Santa Cruz, Ilhéus, Bahia, Brasil

ID Lattes: http://lattes.cnpq.br/7240586669577145 ORCID: http://orcid.org/0000-0001-6156-1205

Endereço eletrônico: eurivalda@ hotmail.com

\section{RESUMO}

Este artigo objetiva analisar e descrever o processo formativo de professores dos anos iniciais que ensinam os conceitos de Comparação Multiplicativa. Uma pesquisa de natureza 
qualitativa, realizada durante um processo formativo com professores que atuavam nos anos iniciais do ensino fundamental. A formação foi organizada em encontros presenciais, virtuais e atividades de prática pedagógica tendo como conteúdo o Campo Conceitual Multiplicativo (CCM) estudado por Gérard Vergnaud. Como resultados, o processo formativo proporcionou indícios de ampliação do conhecimento matemático frente às situaçõesproblema do CCM, fortalecendo: a prática dos professores; elaboração de situações-problema com diferentes complexidades (multiplicação e divisão); o trabalho mediado em sala de aula, observando os esquemas utilizados pelos alunos e os conceitos que ainda precisavam de interferência para efetivar a aprendizagem; possibilidades de novas estratégias para que o professor entenda a construção do conhecimento matemático dos alunos.

Palavras-chave: Estruturas Multiplicativas; Relação Ternária; Formação continuada.

\section{RESUMEN}

Este artículo tiene como objetivo analizar y describir el proceso formativo de los docentes en los primeros años que enseñan los conceptos de Comparación Multiplicativa. Una investigación cualitativa, realizada durante un proceso de formación con profesores que trabajaron en los primeros años de la escuela primaria. La formación se organizó en encuentros presenciales, encuentros virtuales y actividades de práctica pedagógica, teniendo como contenido el Campo Conceptual Multiplicativo (CCM) estudiado por Gérard Vergnaud. Como resultado, el proceso de formación brindó evidencias de la ampliación del conocimiento matemático ante las situaciones problemáticas del CCM, fortaleciendo: la práctica de los docentes; elaboración de situaciones problemáticas con diferentes complejidades (multiplicación y división); el trabajo mediado en el aula, observando los esquemas utilizados por los estudiantes y los conceptos que aún necesitaban interferencia para efectuar el aprendizaje; posibilidades de nuevas estrategias para que el docente comprenda la construcción del conocimiento matemático de los estudiantes.

Palabras clave: Estructuras Multiplicativas; Relación Ternaria; Entrenamiento en curso.

\section{ABSTRACT}

This article aims to analyze and describe the formative process of teachers in the early years who teach the concepts of Multiplicative Comparison. A qualitative research carried out during a training process with teachers who worked in the early 


\section{O ESTUDO DA RELAÇÃO TERNÁRIA PARA O ENSINO DO CAMPO CONCEITUAL MULTIPLICATIVO}

years of elementary school. The training was organized in faceto-face meetings, virtual meetings and pedagogical practice activities, having as content the Multiplicative Conceptual Field (CCM) studied by Gérard Vergnaud. A result, the training process provided evidence of expanding mathematical knowledge in the face of the problem situations of the CCM, strengthening: the practice of teachers; elaboration of problem situations with different complexities (multiplication and division); the work mediated in the classroom, observing the schemes used by the students and the concepts that still needed interference to effect learning; possibilities for new strategies for the teacher to understand the construction of students' mathematical knowledge.

Keywords: Multiplicative Structures; Ternary Relationship; Continuing Education.

\section{INTRODUÇÃO}

Este artigo é parte de uma pesquisa mais ampla ${ }^{\mathrm{i}}$ que tem como objetivo analisar e descrever o processo formativo de professores dos anos iniciais que ensinam os conceitos de Comparação Multiplicativa. A pesquisa contemplava uma proposta de formação continuada que tinha como finalidade estudar e refletir com os professores dos anos iniciais os conceitos do Campo Conceitual Multiplicativo (CCM), em um movimento de constante reconceitualização e reflexão sobre a formação inicial ou continuada (IMBERNÓN, 2009), para discutir e analisar o trabalho que estava sendo realizado com o CCM em uma escola da rede pública de um município localizado no interior da Bahia.

O processo formativo estava organizado em momentos para planejar novas situações e possibilidades para o ensino e a aprendizagem, tendo como fundamentação a Teoria do Campo Conceitual (VERGNAUD, 1996), visto que seus estudos vêm sendo ampliado e aprofundado com a finalidade de fomentar a relação entre a formação de conceitos, o ensino e a aprendizagem.

Este artigo está organizado em quatro seções. A primeira trata do CCM tecendo uma discussão sobre a Relação Ternária; a segunda, apresenta a Relação Ternária; a terceira, a metodologia; a quarta, o estudo da Relação Ternária durante a pesquisa e, por fim, as considerações. 


\section{O Campo Conceitual Multiplicativo: discutindo a Relação Ternária}

Com base nos estudos piagetianos sobre o desenvolvimento da estrutura cognitiva, Gérard Vergnaud elaborou a Teoria dos Campos Conceituais (TCC) tendo como referencial os contextos escolares, propondo uma teoria que possa

[...] proporcionar um quadro para a aprendizagem, interessa à didática; mas não é, por si só, uma teoria didática. A sua principal finalidade é fornecer um quadro que permita compreender as filiações $e$ as rupturas entre conhecimentos, nas crianças e nos adolescentes, entendendo como «conhecimentos», tanto o saber fazer como os saberes expressos (VERGNAUD, 1996, p. 155, grifo do autor).

A TCC fornece um quadro teórico para trabalhar com elementos que fazem parte do desenvolvimento intelectual do indivíduo, tais como, a linguagem, o raciocínio, a percepção e a memória. Concebe o conhecimento em campos conceituais, que é estruturado por um conjunto de situações-problema que dão sentido aos conceitos, procedimentos e representações que são interconectados (VERGNAUD, 1983).

A TCC não é uma teoria didática, mas oferece uma perspectiva para trabalhar com os conceitos, procedimentos e representações matemáticas, em sala de aula. Acreditamos que o professor precisa ter em sua base de conhecimento, saberes relacionados ao objeto matemático (neste caso, o campo da Relação Ternária) e o conhecimento pedagógico que deem suporte ao desenvolvimento de uma prática pedagógica que favoreça a aprendizagem dos alunos. Tais conhecimentos ajudam o professor a analisar os processos pelos quais as crianças adquirem o conhecimento em relação a um dado conceito, permitindo que o mesmo tenha mais clareza sobre o que está sendo ensinado e, assim, possa mediar situações nas quais há a intenção de ampliar as informações dos alunos em relação a determinado conteúdo, com o objetivo de compreenderem sobre o que o professor deseja ensinar.

Nessa mesma direção, Vergnaud (1991, p. 167) desenvolveu um estudo teórico sobre os Campos Conceituais, Aditivo e Multiplicativo para ser desenvolvido em sala de aula, com o objetivo de compreender como os estudantes constroem o pensamento matemático. Um Campo Conceitual engloba um grupo de situações, sendo que nas estruturas aditivas, para a resolução, as situações "exigem uma adição, uma subtração ou uma combinação destas duas operações e, para as estruturas multiplicativas, [...] exigem uma multiplicação, uma divisão ou uma 


\section{O ESTUDO DA RELAÇÃO TERNÁRIA PARA O ENSINO DO CAMPO CONCEITUAL MULTIPLICATIVO}

combinação destas duas operações". Dessa forma, as situações são consideradas como um conjunto de tarefas com grau de complexidade diferentes e essenciais para a aprendizagem dos conceitos. Neste artigo, as tarefas são identificadas por situações-problema.

E, o CCM, ao qual chamaremos de Estruturas Multiplicativas, abrange diversos conceitos, entre eles a: multiplicação, divisão, dobro, metade, triplo, fração, números racionais, funções linear, bilinear e n-linear, razão, taxa, proporção, espaço vetorial, isomorfismo, combinação, produto cartesiano, área, volume.

Para que ocorra a aprendizagem destes conceitos, a criança precisa se deparar com diversas situações, a longo prazo. Portanto, para o professor mediar o trabalho com o CCM, é necessário um período de tempo para planejar, desenvolver e acompanhar como as crianças constroem os referidos conceitos, considerando que as tarefas propostas proporcionem o raciocínio matemático (VERGNAUD, 1996).

O conceito não pode ser limitado a uma definição e, ao trabalhar um conceito é preciso selecionar diversas situações, nas quais esse conceito passa a ter sentido para as crianças (VERGNAUD, 1996). Mas, é importante compreender o que é um conceito. Santana (2012, p. 23) fez essa releitura e o considerou como a "formulação de uma ideia através das palavras e do pensamento". Com base nessa ideia, podemos inferir que podemos observar a apreensão do conceito por meio da maneira como a criança se utiliza da linguagem para explicitar ou registrar um conhecimento.

O CCM, proposto por Vergnaud (1996), envolve uma terna de conjuntos representada como (S, I, R) em que, pode ser explicada da seguinte maneira:

S: o conjunto das situações que dá sentido ao conceito (é a referência para trabalhar o conceito); por exemplo, problemas de proporção, de comparação, combinação;

I: o conjunto dos invariantes, as propriedades para relacionar e operacionalizar, ou seja, elementos para resolver as situações (o significado);

$\mathrm{R}$ : o conjunto das formas de linguagem utilizadas - desenhos, contagem pictórica, os diagramas - para representar os procedimentos (o significante).

Com relação ao conjunto de situações, cabe ao professor elencá-las de maneiras diferentes de modo a propiciar não apenas a conexão entre os conceitos dos campos aditivo e multiplicativo, isto é o que chamamos de filiações; mas, é necessário também a compreensão de estruturas mais complexas que possibilitem a passagem de um conhecimento para outro, isto é, as rupturas. Nesse caso, a filiação acontece quando o aluno recorre a adição para resolver 


\section{O ESTUDO DA RELAÇÃO TERNÁRIA PARA O ENSINO DO \\ CAMPO CONCEITUAL MULTIPLICATIVO}

situações-problema do campo multiplicativo, por meio da soma de parcelas iguais (Campo Aditivo).

Nesse caso, o professor, enquanto mediador do ensino e da aprendizagem, elabora um conjunto de tarefas (situações) para que haja reflexão sobre as condições de resolvê-las, isto é, proporcionar caminhos para aprendizagem de novos conhecimentos; e a ruptura é alcançada à medida que o aluno compreende que a adição de parcelas iguais não é suficiente para resolver algumas situações-problema que envolvam as Estruturas Multiplicativas.

Assim, a aprendizagem é alcançada quando o aluno dispõe de competências necessárias (sobre adição, subtração, multiplicação, divisão etc.) para resolver situações diferentes, para as quais devem ser desenvolvidas com determinada habilidade. As situações-problema ajudam no ensino e na aprendizagem de diferentes conceitos e procedimentos. Esses processos não são imediatos, requerem um tempo que é individual para a aprendizagem de cada um, em sala de aula (VERGNAUD, 1983).

Para compreender a formação desses diversos conceitos das Estruturas Multiplicativas, têm-se duas relações: a Relação Quaternária que é organizada com situações de Proporção Simples entre conjuntos de naturezas distintas; e a Relação Ternária que envolve uma relação "entre 3 quantidades, das quais uma é o produto das duas outras ao mesmo plano numérico e no plano dimensional" (VERGNAUD, 2014, p. 253).

\section{RELAÇÃO TERNÁRIA}

A Relação Ternária é uma ligação de "três elementos entre si", os quais podem ser "pessoas, números, conjuntos... enfim, objetos lógicos de natureza bem diversa”. Por exemplo: "Pedro está entre André e Joana", "sete é quatro a mais que três" (VERGNAUD, 2014, p. 57 grifos do autor).

Estudos de Magina, Merlini e Santos (2012) e Santos (2015) apresentam a organização do CCM, no que se refere as Relações Quaternária e Ternária. Neste artigo focamos a discussão na Relação Ternária que está estruturada em dois eixos: Comparação Multiplicativa e Produto de Medidas. Conforme a Figura 1, o eixo da Comparação Multiplicativa compõe três classes que são: Relação desconhecida, Referente desconhecido ou Referido desconhecido. 
Figura 1 - Esquema do Campo Conceitual Multiplicativo

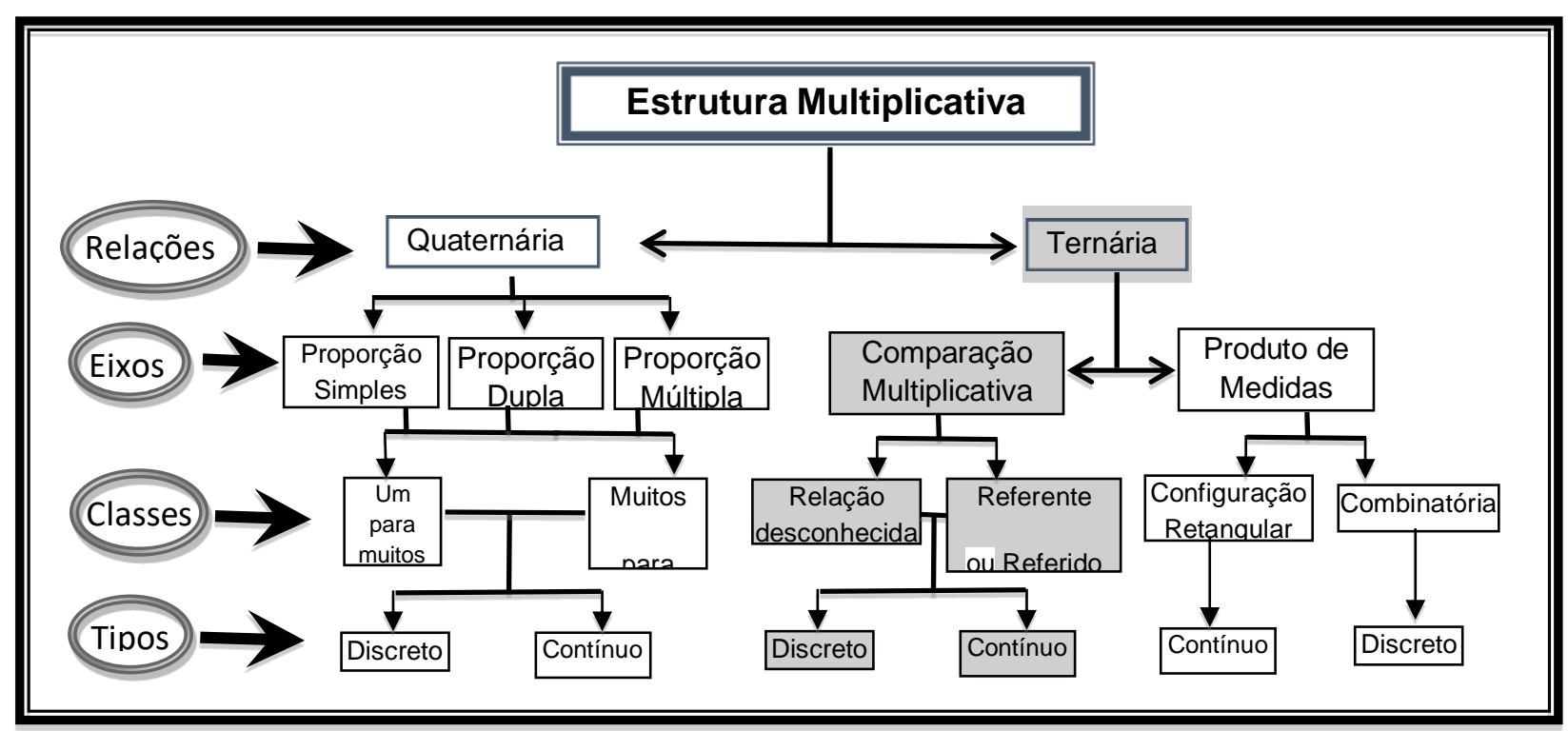

Fonte: Magina, Merlini e Santos (2012) e Santos (2015).

As classes das relações estão associadas às diferentes complexidades fornecidas pelas situações para que o estudante possa avançar na sua compreensão. Em nossas pesquisas, percebemos que o Referente e o Referido desconhecido estão em um mesmo quadro (Figura 1), mas têm significados diferentes. Dessa forma, adaptamos as ideias desses autores identificando cada classe (Relação desconhecida, Referente e Referido desconhecido) no eixo da Comparação Multiplicativa separadamente e passamos a assumir a Figura 2. No detalhamento do nosso estudo deparamo-nos com situações-problema de Comparação Multiplicativa que indicaram a presença das três classes, em separado, na sua resolução e com níveis de complexidade diferentes.

É possível observar (Figura 2) que na Relação Ternária para o eixo da Comparação Multiplicativa apresentamos as três classes: o Referente é a quantidade que serve como referência para a comparação estabelecida; o Referido é a quantidade que resulta da comparação estabelecida; e a Relação é a quantidade que estabelece a relação entre referente e referido.

As situações que representam a relação de dobro, triplo, metade, quádruplo, fração, função linear, bilinear, podem ser resolvidas por meio da operação de multiplicação ou de divisão e são exemplos de situações de Comparação Multiplicativa. Nesse contexto, consideramos três classes para o eixo Comparação Multiplicativa: 1) Relação desconhecida,

2) Referente desconhecido e 3) Referido desconhecido. 
Figura 2- Estrutura Multiplicativa considerada para os nossos estudos

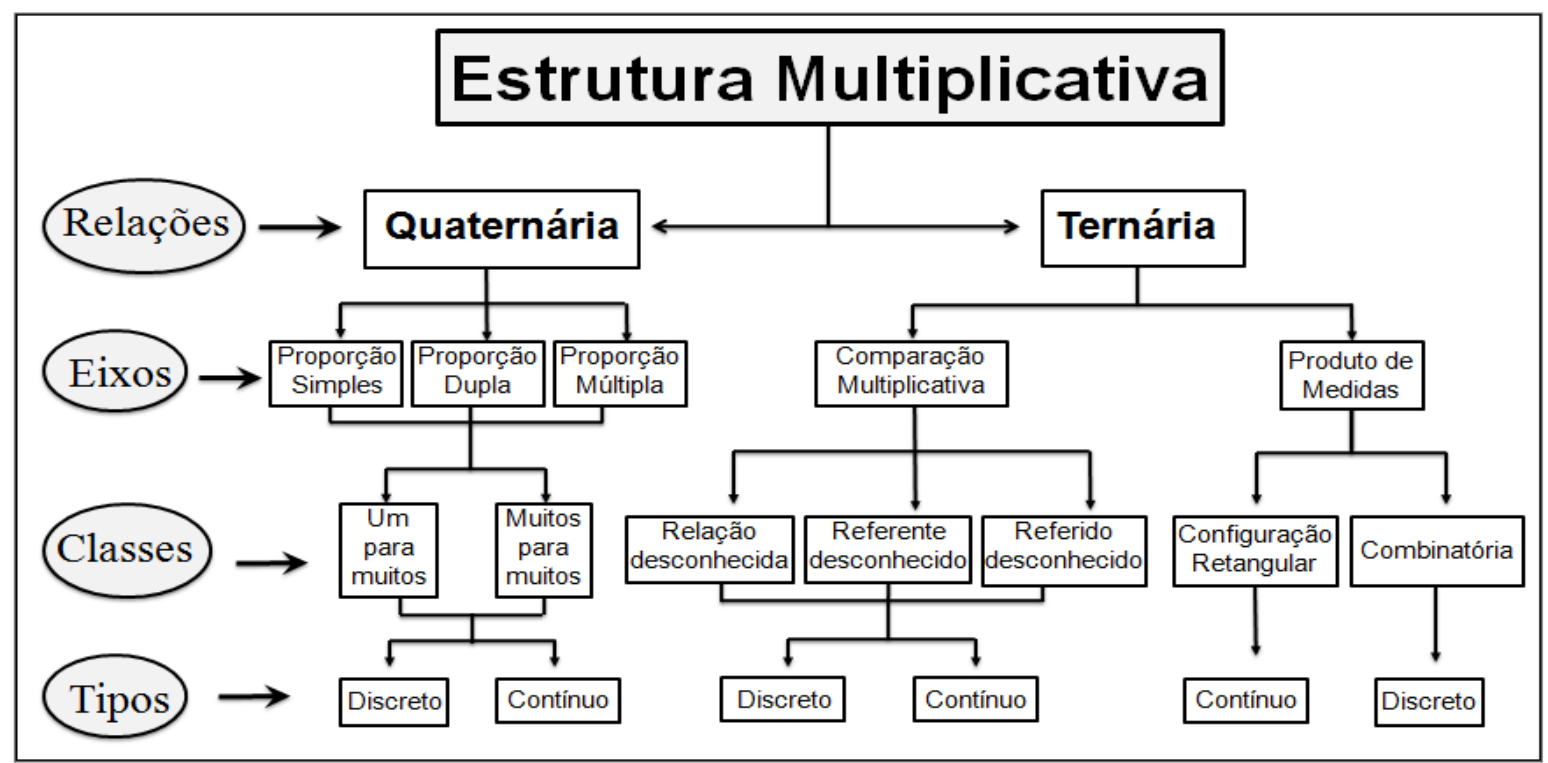

Fonte: Adaptado de Magina, Merlini e Santos (2012) e Santos (2015).

Por se tratar de uma relação Ternária, os três elementos são da mesma grandeza e estão relacionados por meio da comparação estabelecida. A Relação desconhecida é o operador que transforma uma medida, trata-se de um escalar (valor inteiro). "Uma transformação opera sobre uma medida para resultar em uma medida" (VERGNAUD, 2014, p. 202). Nesse eixo, as medidas são o Referente e o Referido.

O Referente é a medida referencial para estabelecer a comparação entre os elementos. O $\underline{\text { Referido }}$ é a medida que passa pela transformação, depende do Referente. Assim, quando a Relação é desconhecida em uma situação-problema, o Referente e o Referido são conhecidos, do mesmo modo, quando o Referente é desconhecido, a Relação e o Referido são conhecidos, e com o Referido desconhecido são dadas a Relação e o Referente. Entre o Referente e o Referido, a Relação exprime a ideia de 'vezes maior', ou 'vezes menor'.

Vejamos exemplos das situações que dão sentido ao eixo da Comparação Multiplicativa.

A Situação 1, na Figura 3, apresenta o seguinte enunciado:

Cido tem uma coleção de 6 carrinhos e José tem uma coleção de 24 carrinhos. Quantas vezes a coleção de Cido é menor que a de José? 
CAMPO CONCEITUAL MULTIPLICATIVO

\section{Figura 3 - Proposta de resolução para a Situação 1}

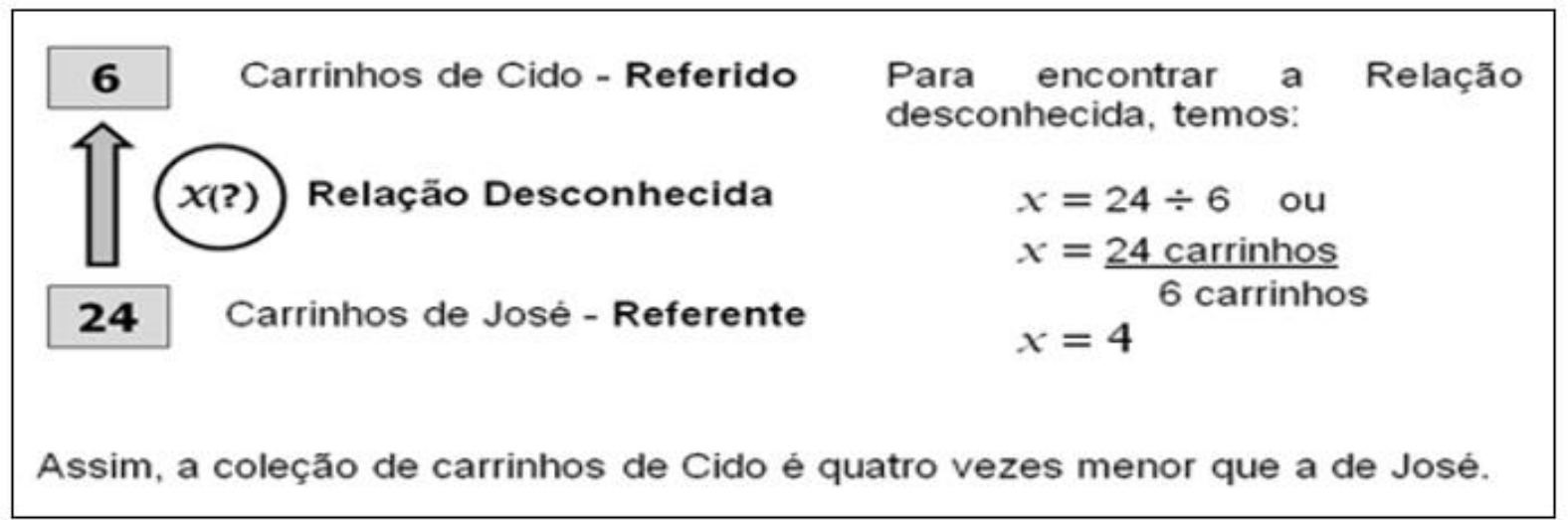

Fonte: Material de pesquisa produzido nos estudos do OBEDUC/E-Mult (2014/2015).

Na situação, a coleção de carrinhos de Cido está sendo comparada com a de José, o que nos auxilia identificar a coleção de José como um Referente (a referência) e a de Cido como o Referido. Assim, a classe desconhecida é a Relação (vezes menor) estabelecida entre eles.

A proposta de resolução apresentada na Figura 3 para determinar a Relação entre as quantidades de carrinhos, faz uso dos diagramas de Vergnaud, que buscam representar e compreender a Relação entre as quantidades (cálculo relacional) e a partir dessa compreensão resolver com uso da operação (na situação 1, a divisão).

Conforme a resolução, destacamos que a grandeza (quantidade de carrinhos) apresenta duas medidas (6 e 24) e entre as medidas há uma Relação que é desconhecida, mas sabemos que a quantidade de carrinhos de Cido é tantas vezes menor que a de José. Isso indica que o Referido é menor que o Referente e para encontrar a Relação é preciso dividir essas medidas que estão sendo comparadas ( 24 carrinhos $\div 6$ carrinhos), obtendo a Relação desconhecida, que é o Escalar Multiplicativo quatro. Isto é, a coleção de carrinhos de Cido é quatro vezes menor que a de José.

A situação 1 (Figura 3) mostra um exemplo da Relação Ternária, eixo da Comparação Multiplicativa, classe Relação desconhecida, envolvendo a grandeza do tipo discreto, cuja operação de resolução é uma multiplicação. 
A Figura 4 destaca a seguinte situação:

Ontem Tonho tinha 18 figurinhas. E hoje ele tem 3 vezes menos. Quantas figurinhas ele tem hoje?

Figura 4 - Proposta de resolução para a Situação 2

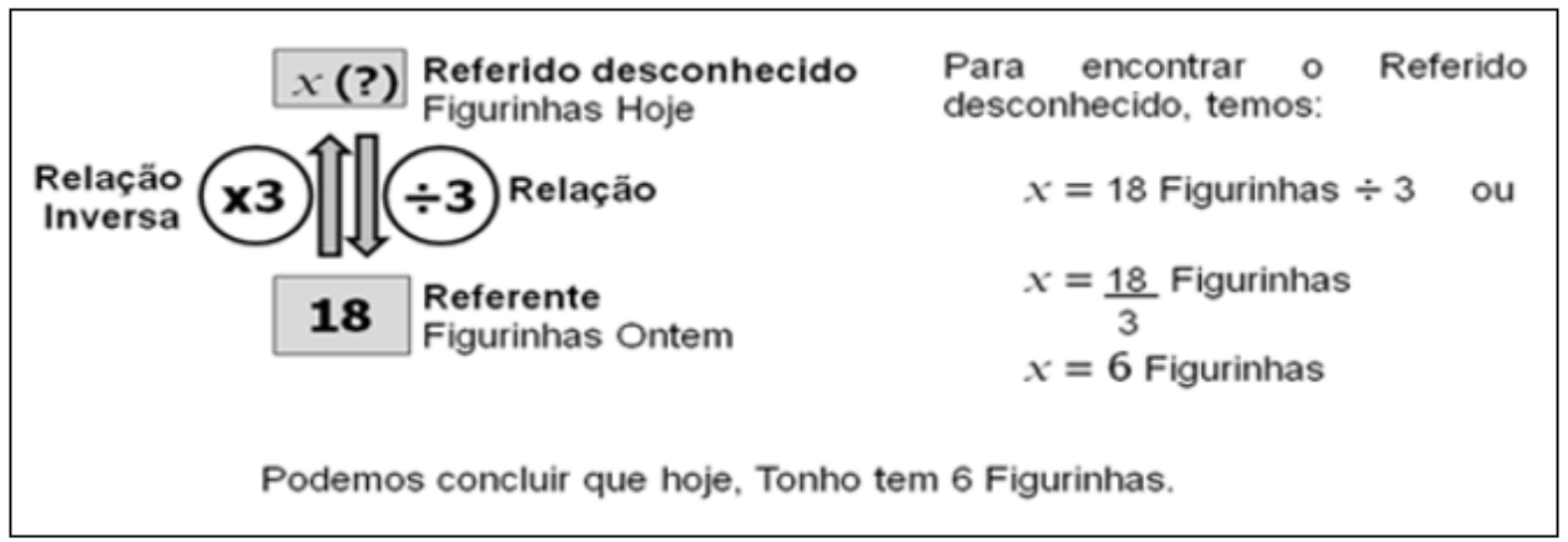

Fonte: Material de pesquisa produzido nos estudos do OBEDUC/E-Mult (2014/2015).

Essa situação apresenta uma relação entre as medidas, Referente e Referido, que é três vezes menor. A quantidade procurada (figurinhas hoje) está sendo comparada com a quantidade de figurinhas que Tonho tinha ontem, o Referente, pois se destaca como referência para encontrar o número de figurinhas que ele tem hoje. Logo, a grandeza (figurinhas hoje) é o Referido.

Para resolver essa situação é importante, inicialmente, analisar a Relação entre o Referente e o Referido, “3 vezes menos”. Essa expressão suscita a operação de divisão, o que nos permite concluir que, neste caso, o operador (x3) é a Relação inversa multiplicativa. Assim, essa é uma situação da Relação Ternária, eixo da Comparação Multiplicativa, classe Referido desconhecido, com grandeza do tipo discreto e a operação utilizada para encontrá-lo é a divisão.

Na situação 3, Figura 5, temos a resolução para a seguinte situação:

A filha de Madá tem 30 anos. Sabendo que ela é duas vezes mais nova que a mãe, qual a idade de Madá? 
CAMPO CONCEITUAL MULTIPLICATIVO

\section{Figura 5 - Proposta de resolução para a Situação 3}

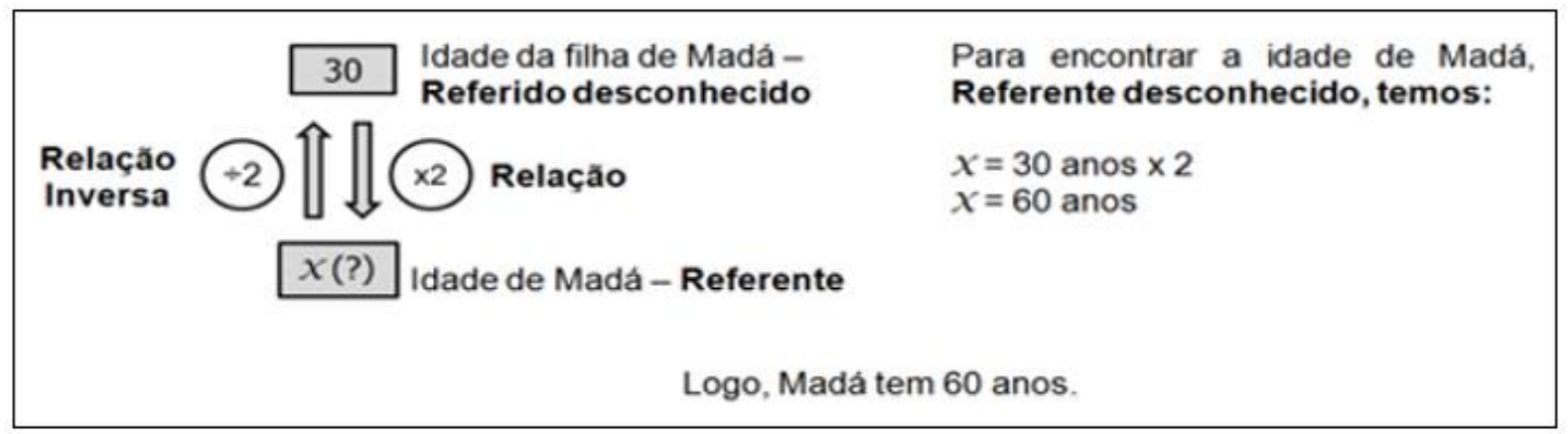

Fonte: Material de pesquisa produzido nos estudos do OBEDUC/E-Mult (2014/2015).

Nessa situação, a Referência é desconhecida (idade de Madá), por isso torna-se necessário que o Referido (idade da filha) seja transformado pela Relação (duas vezes mais nova). Pelo enunciado, Madá tem o dobro da idade de sua filha e para resolver a situação multiplicamos o Referido e a Relação (30 anos x2), obtendo a idade de Madá (60 anos). Podemos observar que o termo utilizado para se referir a idade da filha de Madá, "mais nova", revela a ideia de divisão e o operador $(\div 2)$ é o inverso multiplicativo.

A Figura 5 apresenta um exemplo de uma situação da Relação Ternária, eixo da Comparação Multiplicativa, classe Referente desconhecido, com grandeza do tipo discreto, pois estamos considerando a idade em anos completos, e a operação utilizada para resolvê-la é a multiplicação.

Para entender a dimensão das Estruturas Multiplicativas é necessária uma compreensão conceitual, bem como, a possibilidade de pensar a formação do conceito com a finalidade de romper com o campo aditivo e, assim, ampliar o repertório de conhecimento matemático tanto para o professor quanto para os estudantes.

\section{METODOLOGIA}

A pesquisa teve uma abordagem qualitativa desenvolvida no ambiente natural de uma escola (LÜDKE; ANDRÉ, 1986), tendo como objetivo de pesquisa analisar e descrever o processo formativo de professores dos anos iniciais que ensinam os conceitos de Comparação Multiplicativa. 
A pesquisa foi realizada com professores de uma escola pública, que atua com os anos iniciais do Ensino Fundamental, que participaram de um processo formativo que tinha como finalidade estudar as Estruturas Multiplicativas.

Os participantes assinaram o Termo de Consentimento Livre e Esclarecido (TCLE) e para preservar a identidade, foram identificados por Profa. Bia, Profa. Laís, Profa. Luiza, Profa. Lia, Profa. Luna, Profa. Laura, Profa. Lilia e os pesquisadores como Pesq.1, Pesq. 2, Pesq. 3 etc.

Para a produção de dados, utilizamos os seguintes instrumentos: entrevista, diário de campo com anotações em momentos de dois dos encontros de formações presenciais e dois dos virtuais. A entrevista e observação em sala de aula só aconteceram com a Profa. Bia por ser a única que disponibilizou o acesso das pesquisadoras às suas aulas.

A formação fez parte das atividades do projeto de pesquisa OBEDUC fomentado pela Capes, com encontros presenciais e virtuais. Elegemos como eixo de análise o estudo sobre a Relação Ternária.

O estudo e discussão sobre a Comparação Multiplicativa foi realizado em dois encontros virtuais, com duração de uma hora a cada 15 dias. Para o primeiro encontro os professores receberam uma cópia impressa dos textos ${ }^{\mathrm{ii}}$ a serem estudados e discutidos durante os encontros virtuais. Esse material, também, estava disponibilizado no Ambiente Virtual de Aprendizagem (AVA).

Inicialmente, os participantes da formação (pesquisadores e professores) receberam o login e senha para acesso ao AVA. A formação virtual foi organizada com o estudo e discussão de textos sobre o CCM e a Relação Ternária, sempre direcionando para pensar as situações que podem ser trabalhadas, ensinadas e aprendidas em sala de aula, considerando a Comparação Multiplicativa e os conteúdos envolvidos.

Foram dois os encontros presenciais voltados diretamente para a discussão da Comparação Multiplicativa. No primeiro foi feita a discussão teórica e os professores elaboraram duas situações-problemas para a prática na sala de aula. $\mathrm{O}$ segundo encontro se destinou a discussão dos resultados da prática de ensino desenvolvida com os estudantes em sala de aula. 


\section{O ESTUDO DA RELAÇÃO TERNÁRIA PARA O ENSINO DO \\ CAMPO CONCEITUAL MULTIPLICATIVO}

\section{O ESTUDO DA RELAÇÃO TERNÁRIA DURANTE A PESQUISA}

Nos encontros virtuais aconteciam a discussão teórica, fundamentada nos estudos de Vergnaud $(1983 ; 1996 ; 2009 ;$ 2014) com o objetivo de aprofundar os estudos relacionados às Estruturas Multiplicativas. Em cada encontro teve um mediador, mestrando ou graduando, responsável por iniciar a discussão fazendo questionamentos e fomentando o diálogo entre os membros.

Nos encontros presenciais, além da discussão teórica, os professores elaboravam situações-problema que eram discutidas com seus colegas e, posteriormente, respondidas por seus alunos. Em sala de aula, a proposta de resolução destas situações seguiu os passos como: realização do trabalho em grupo e individual; análise das soluções; intervenção por meio dos acertos; observação de erros nos esquemas de resolução; e, participação dos alunos na discussão.

No primeiro encontro virtual a mediadora começou a discussão com a leitura das situações-problema presentes no texto indicado para estudo (Quadro 1), referentes a Relação Quaternária, as quais apresentavam diferentes estratégias para resolvê-las.

Quadro 1 - A resolução das situações-problema destacadas no texto referência

\begin{tabular}{|c|c|c|}
\hline Problema 1 & Problema 2 & Problema 3 \\
\hline $\begin{array}{c}\text { Dona Benta gasta } 4 \text { ovos para } \\
\text { fazer } 1 \text { bolo. Ela quer fazer } 3 \\
\text { bolos. Quantos ovos ela vai } \\
\text { gastar? }\end{array}$ & $\begin{array}{c}\text { Dona Benta gasta } 4 \text { ovos para } \\
\text { fazer } 1 \text { bolo. Ela quer fazer } 8 \\
\text { bolos. Quantos ovos ela vai } \\
\text { gastar? }\end{array}$ & $\begin{array}{c}\text { Dona Benta faz } 35 \text { bolos por } \\
\text { mês e ela gasta } 4 \text { ovos em cada } \\
\text { bolo. Quantos ovos ela gastará } \\
\text { no mês? }\end{array}$ \\
\hline 4 ovos +4 ovos +4 ovos $=12$ & 8 bolos $X 4$ ovos & $\begin{array}{r}35 \\
\times \quad 4 \\
140\end{array}$ \\
\hline
\end{tabular}

Fonte: Elaborado por Magina, Santos e Merlini (2014).

A discussão iniciou refletindo sobre as possibilidades de resolver situações multiplicativas. Na primeira, o problema é solucionado pela adição de parcelas $(4+4+4=12)$; a segunda pela multiplicação, a conta na horizontal $(8 \times 4=32)$; e a terceira, com um número maior (35), uma multiplicação ( 35 x $4=140$ ), com o algoritmo (conta na vertical).

Entre as respostas apresentadas (Quadro 1), a Profa. Bia observou que o contexto das situações era o mesmo e que a diferença estava nas quantidades das grandezas. Continuando a discussão, Profa. Luna relatou que o aumento das parcelas sugere um método menos cansativo e dá início a multiplicação no ensino dos anos iniciais. A Profa. Bia retomou a discussão e 
enfatizou inferindo que para realizar esse processo "[...] o aluno começa a perceber a existência de um modo mais prático de resolução” (Diário de campo, 2015).

Ao longo da discussão, a Pesq. 1 argumentou uma mudança no campo numérico. Indicou, ainda, que a multiplicação pode significar também uma repetição de parcelas, mas o fato de aumentar a quantidade a torna extensa. Além disso, lembrou que devem ser considerados outros raciocínios, isto é, a multiplicação pode diminuir quando multiplicamos dois números pertencentes ao conjunto dos Números Racionais (maior que zero e menor que um). Essa é a importância da ideia de romper com a multiplicação por meio da adição de parcelas repetidas.

A Comparação Multiplicativa foi tema do segundo encontro virtual e, buscando construir os conceitos da Relação Ternária, retomamos a discussão da Relação Quaternária para definir e estabelecer diferenças entre as duas relações.

$[\ldots]$

Profa. Luiza - Quaternária envolve proporções e a ternária não.

Profa. Bia - A quaternária é a relação entre três elementos para obter um quarto.

Profa. Luiza: - Com a ternária não podemos fazer o esquema usado na quaternária porque só temos dois elementos e procuramos o desconhecido.

Profa. Bia - Essa era a minha dúvida. Se colocaria tudo direto.

Pesq. 1 - Profa. Bia, é melhor assumir que existe uma relação entre três quantidades.

- Acrescento na fala de Profa. Luíza que na ternária temos uma única grandeza.

Pesq. 4 - As relações ternárias são relações que, como o nome indica, ligam três elementos entre si.

Pesq. 1 - Um exemplo: 'Bia tem 4 reais e Lia tem 3 vezes essa quantidade. Quantos reais tem Lia?'

Profa. Bia - Esse exemplo é de comparação multiplicativa, certo? - É Ternária.

Pesq. 1 - Certo, Profa. Bia. - Por que ternária?

Profa. Laís - É a relação entre duas quantidades para se obter uma terceira quantidade.

Profa. Bia - Relação entre três elementos.

Profa. Luiza - Relação entre dois elementos e se busca um terceiro - Ternária.

Pesq. 1 - Por que Profa. Luíza? 
Profa. Luiza - Porque relaciona dois elementos e se busca um terceiro elemento. Nesse caso de uma mesma natureza.

Pesq. 1 - Isso Profa. Luiza. Quando a relação é entre três quantidades ou elementos, chamamos de ternária ( $2^{\circ}$ encontro virtual).

Nesse diálogo, a Profa. Bia assume um posicionamento mais assertivo a respeito da classificação das situações de Comparação Multiplicativa. Pesq. 1 acrescentou que a Relação Ternária ocorre entre três elementos ou quantidades e exemplificou com situações que não envolviam medidas: "a carteira de Lília está antes da carteira de Lia e depois da carteira de Luíza". Os exemplos estão associados ao campo conceitual adotado por Vergnaud (2009) para exemplificar situações dessa relação.

Diante disso, a Pesq. 1 ressaltou que o fato de uma situação ser classificada como Relação Ternária ou Quaternária não é estritamente do campo multiplicativo, ou seja, “[...] ser ternária é estar relacionando três elementos [...] ser quaternária é relacionar quatro elementos [...] essas relações valem em qualquer campo conceitual” ( $2^{\circ}$ Encontro Virtual).

No segundo encontro, percebemos o avanço dos professores na aprendizagem dos conceitos das Estruturas Multiplicativas e se sentiam à vontade para expor as suas dúvidas na discussão, isso proporcionou uma riqueza de conhecimento, numa construção de aliança produtiva $^{\text {iii }}$ (LÜDKE, 2001), concretizada na articulação entre universidade e escola, um processo formativo para estudar conceitos referentes às relações Quaternária e Ternária.

No quarto encontro virtual estudamos a Relação Ternária, eixo da Comparação Multiplicativa, classe Relação desconhecida, Referente desconhecido e Referido desconhecido. Para iniciar a discussão, o mediador propôs que fossem apresentadas características de situações pertencentes a esse eixo.

As respostas apresentadas pelas professoras demonstram haver conflito conceitual quanto a classificação.

$[\ldots]$

Profa. Bia: - Pode ser entre mais de duas quantidades.

- Podendo ser de múltipla proporção, de comparação.

Pesq. 1: - Ternária é uma relação com 3 elementos. 
A Pesq. 1 exemplifica questionando sobre quais elementos estão sendo relacionados na frase 'João está sentado entre Alda e Silvana'.

Profa. Bia: - Pessoas.

Profa. Laís: - Pessoas, mesma natureza.

Mediador: - Os elementos são: João, Bia e Luiza.

Pesq. 1: - Elementos é o que estamos relacionando. [...] Natureza são as pessoas.

Em seguida, foi apresentada a seguinte situação para discutir a Comparação Multiplicativa enfatizando a classe - Relação, Referido, Referente.

Mediador: - Qual elemento está sendo solicitado na situação: Cláudio tem 10 livros e Marina possui 3 vezes mais que Cláudio. Quantos livros ela tem?

Pesq. 4 - Então, em qual classe essa situação se encontra?

Profa. Bia - Relação desconhecida.

Pesq. 1 - A relação é desconhecida?

Profa. Laís - Acho que é referido.

Profa. Laura - Não, a relação é de três vezes.

Profa. Luíza - Referido desconhecido.

Profa. Bia - Referido desconhecido?

Profa. Luíza - Referente é Cláudio.

Pesq. 5 - Qual a relação de livros entre Cláudio e Marina?

Profa. Luíza - Três vezes.

Profa. Bia - Quantidade de livros 3x.

Pesq. 5 - Então, a relação é desconhecida?

Profa. Bia - Desconhecida.

Profa. Laura - A referência é Cláudio.

Pesq. 1 - Referente é aquele valor que a partir dele podemos determinar o valor do outro. [...] Para saber a quantidade de livros de Marina, precisamos saber a quantidade de livros de Cláudio. Observem que a quantidade de livros de Marina depende da quantidade de Cláudio. Por isso a quantidade de livros de Cláudio é o referente.

$[\ldots]$ ( $4^{\mathrm{o}}$ Encontro virtual). 
Observe que a Profa. Bia inicia colocando como característica da Comparação Multiplicativa a proporção múltipla, revelando não compreender as características de uma situação classificada como pertencente a Comparação Multiplicativa. Mesmo após a apresentação dos exemplos, ela continua sem compreender quais são os elementos de uma situação classificada nesse eixo. Ao final ela concorda com a classificação feita pela pesquisadora, que se busca na situação o referido, mas não deixa explícito a sua própria compreensão.

Na Figura 6 apresentamos uma possibilidade de resolução dessa situação para discutir a Comparação Multiplicativa com a identificação da classe Relação, Referido e Referente.

Figura 6 - Resolvendo situação de Comparação Multiplicativa

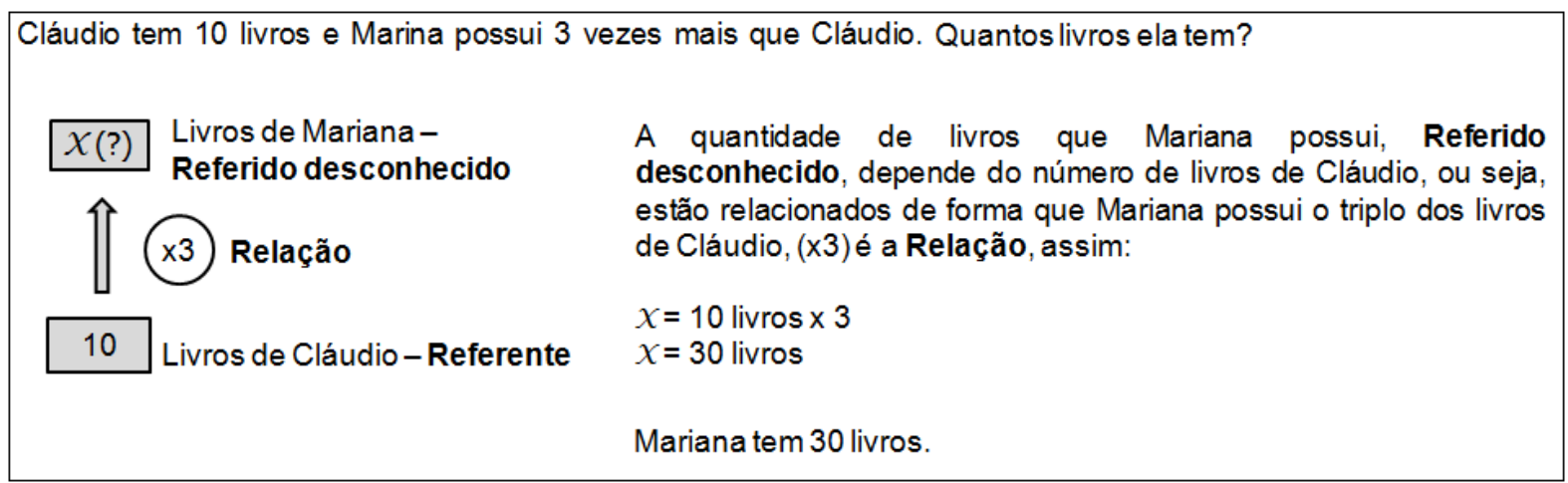

Fonte: Material elaborado na pesquisa (2015).

A situação-problema apresentada para discussão é classificada como Relação Ternária, eixo da Comparação Multiplicativa, classe Referido desconhecido, grandeza do tipo discreto e a multiplicação é a operação utilizada para resolvê-la (Figura 6).

Para continuar a discussão, outra situação-problema foi apresentada:

$[\ldots]$

Pesq. 1 - Qual elemento está sendo solicitado na situação: Pedro tem 45 figurinhas e 15 bolas de gude. Quantas vezes a quantidade de figurinhas é maior do que as bolas de gude?

Profa. Luíza - Relação

Profa. Bia - Quantidade de figurinhas.

Profa. Laura - É a relação desconhecida.

Pesq. 1 - Isso Profa. Laura e Profa. Luiza, a relação é desconhecida. 
Profa. Bia - A relação é desconhecida, mas o elemento solicitado é o número de figurinhas, certo?

Pesq. 1 - Profa. Bia, a quantidade de figurinhas está colocada.

Profa. Bia - Xiii!!!

$[\ldots]\left(4^{\circ}\right.$ Encontro virtual $)$.

A seguir, apresentamos uma possibilidade de resolver a situação (Figura 7) apresentada no encontro virtual que é classificada como Relação Ternária, eixo da Comparação Multiplicativa, classe Relação desconhecida, grandeza do tipo discreto e a operação utilizada para resolvê-la é a divisão.

\section{Figura 7 - Proposta de resolução}

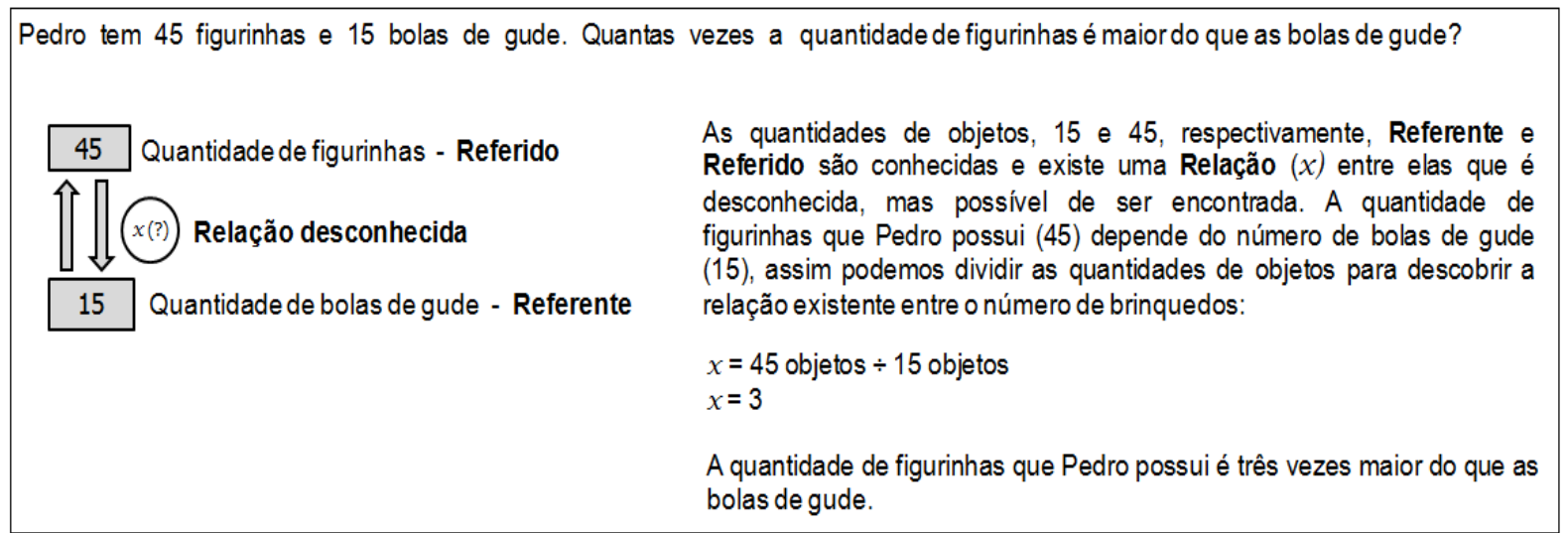

Fonte: Material elaborado na pesquisa (2015).

A discussão no encontro virtual não possibilitava organizar as situações-problema (Figuras 6, 7 e 8) e, para tentar sanar as dúvidas em relação à Comparação Multiplicativa, outros questionamentos foram realizados, conforme mostra o diálogo:

$[\ldots]$

Pesq. 1 - Qual elemento está sendo solicitado na situação: Clara tem a metade da idade de Joana. Se Clara tem 7 anos, qual a idade de Joana?

Profa. Bia - Idade de Joana.

Pesq. 1 - Profa. Bia, nesse exemplo qual elemento está sendo solicitado: REFERENTE, REFERIDO OU RELAÇÃO?

Profa. Luiza - Referente desconhecido.

Profa. Laís - Referente. 
Profa. Luiza - Clara é referida, a relação está explícita.

Profa. Lícia - Referente desconhecido?

Profa. Luiza - O que se procura é o referente.

Profa. Bia - Acho que relação.

Profa. Luiza - Referente

$[\ldots]\left(4^{\circ}\right.$ Encontro virtual $)$.

A Profa. Bia ainda estava confusa quanto a identificação da classe (Referente, Referido, Relação) das situações-problema propostas (Figuras 6 e 7) para discutir a Comparação Multiplicativa, por isso a Pesq. 1 tentou esclarecer alguns conceitos:

$[\ldots]$

Pesq. 1 - Profa. Bia, a relação é o valor que compara duas quantidades.

Profa. Luiza - No caso, a metade.

Pesq.1 - Isso Luiza. A quantidade de Clara depende da quantidade de quem?

Prof. Luna - De Joana

Profa. Bia - De Joana. - Joana referente.

Pesq.1 - Isso gente. A quantidade de Joana é a referência para determinar a quantidade de Clara.

- Assim, Joana REFERENTE. Entenderam?

Profa. Bia: - Certo.

$[\ldots]$

Profa. Bia: - Sim então nessa situação buscamos?

Pesq. 1 - Buscamos?

Profa. Laís - O referente, Profa. Bia.

Pesq. 2 - A idade de Joana, por isso é o referente desconhecido.

Profa. Bia - Obrigada Pesq. 2 e Laís.

$[\ldots]\left(4^{\circ}\right.$ Encontro virtual).

A situação-problema é uma Relação Ternária, eixo da Comparação Multiplicativa, grandeza do tipo discreto, pois estamos considerando a idade em anos completos e a multiplicação é a operação para resolvê-la (Figura 8). 


\section{Figura 8 - Proposta de resolução}

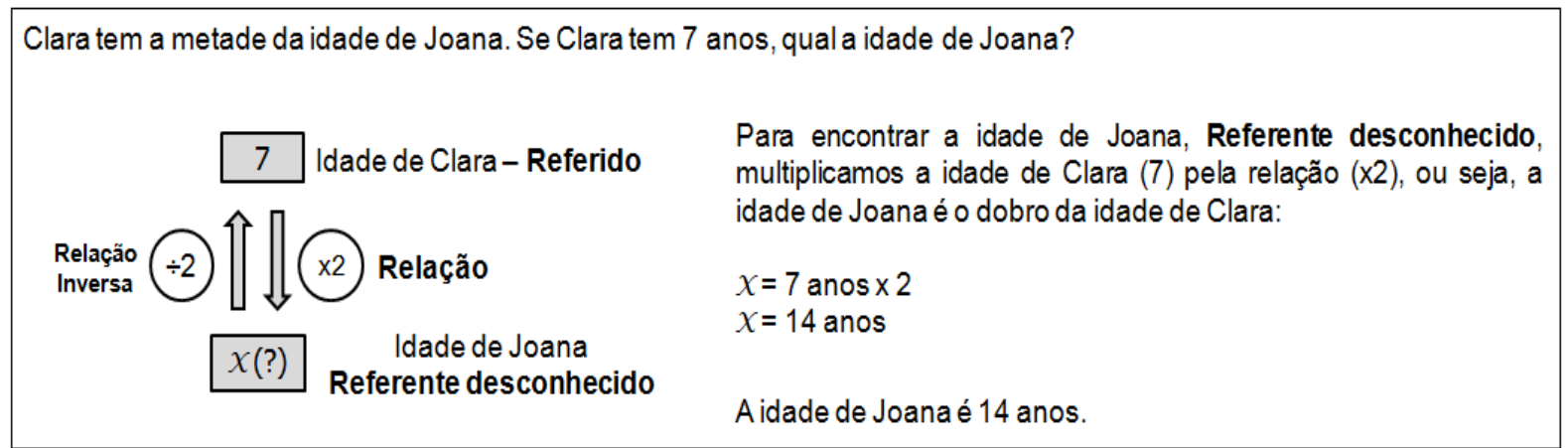

Fonte: Material elaborado na pesquisa (2015).

A dificuldade de resolução dessa situação-problema (Figura 8) talvez esteja na interpretação do enunciado, o qual destaca a metade, ou seja, uma ideia de divisão e a operação de resolução envolve uma multiplicação. Diante dessa observação e mediante as dúvidas dos professores, destacamos a importância de discutir os elementos, as operações envolvidas e as possibilidades de resolução da situação (VERGNAUD, 1983).

Além disso, destacamos que a dinâmica de participação dos professores nesse encontro foi um ponto forte, visto que agregou momentos ricos com trocas de saberes, pois apresentaram suas respostas, de acordo com o que haviam entendido (ou não) sem resistência, por estarem dispostos a compreender o que ensinam nas aulas de Matemática, ou mesmo como tornar o ensino do CCM mais claro.

A Comparação Multiplicativa foi o tema do quinto encontro presencial. Nesse momento, buscou-se enfatizar a importância de trabalhar o contexto social, da comunidade escolar, o incentivo a interlocução com as outras áreas e a elaboração das estratégias utilizadas para a construção dos conceitos multiplicativos em sala de aula.

Apresentamos as situações elaboradas pelo grupo de professores do $5^{\circ}$ ano (Figura 9) nesse encontro, depois foram resolvidas pelos estudantes em suas salas de aula e discutidas na formação seguinte. 


\section{Figura 9 - Atividade elaborada pelos professores do $5^{\circ}$ ano}

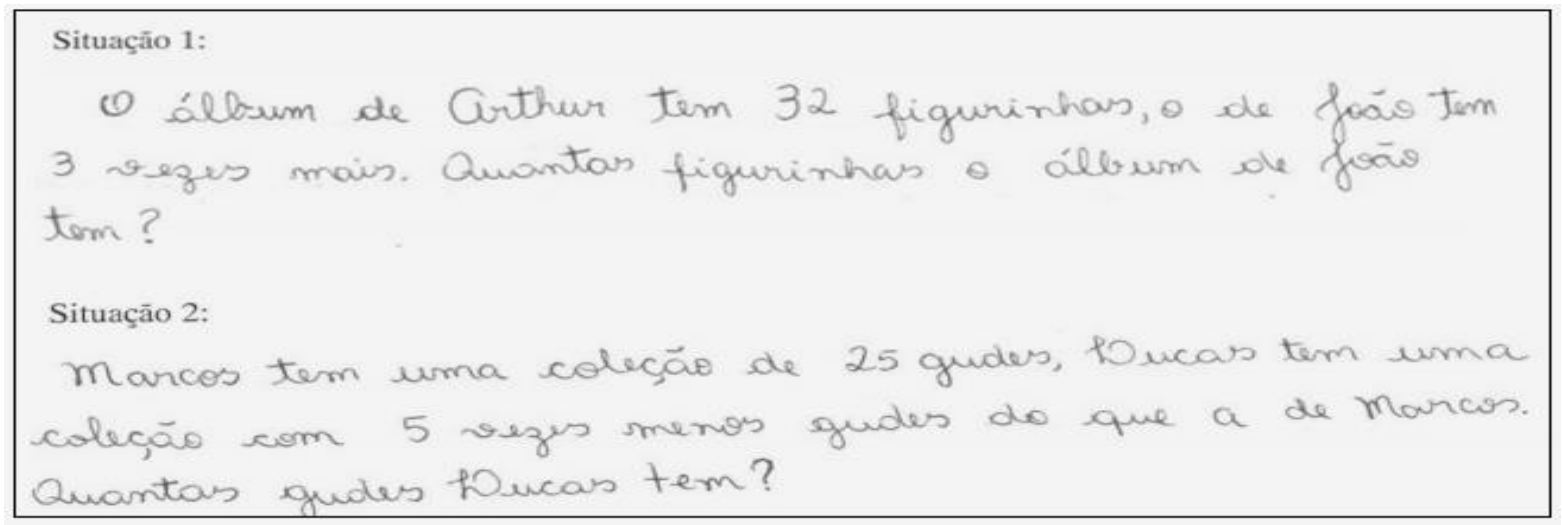

Fonte: Material elaborado na formação presencial do OBEDUC/E-Mult (2015).

A estratégia sugerida para o trabalho em sala de aula, com essas situações apresentadas na Figura 9, foi: distribuir fichas numeradas e fazer comparações com questionamentos sobre ‘quantas vezes mais' ou 'quantas vezes menos' um possuía em relação ao outro.

Como parte da organização da formação, no encontro seguinte os professores apresentavam como realizaram a atividade planejada. $\mathrm{Na}$ análise das situações, observaram que os estudantes já conseguiam responder identificando as grandezas, outros colocavam a resposta sem registrar esquema de resolução. O que revela uma possibilidade de cálculo mental, enquanto outros ainda fazem uso da adição e da subtração. Com base nesses dados, podemos inferir que as expressões 'vezes mais' e 'vezes menos' contidas nas situações tenham influenciado nas suas escolhas. Resultados semelhantes quanto ao uso dessas operações na resolução de situações de Comparação Multiplicativa foram encontrados nos estudos de Almeida (2017).

Notamos nos diálogos durante o encontro formativo, que Profa. Bia e seus colegas sentiram dificuldade em compreender os termos "vezes mais" e "vezes menos" como elementos que recorrem a uma operação multiplicativa, pois confundiam com a aditiva e resistiam a buscar um posicionamento de abertura para essa "nova" aprendizagem. Os professores também estavam tentando fazer uma ruptura entre os Campos Aditivo e a Multiplicativo.

Ao planejar as atividades para ensinar situações da Comparação Multiplicativa, a Profa. Bia seguiu o planejamento elaborado na formação (Diário de campo da pesquisadora). Essa estratégia possibilitou o envolvimento da turma diante das situações apresentadas, pois fizeram parte do processo de aprendizagem, fez sentido para eles (VERGNAUD, 1983). 


\section{O ESTUDO DA RELAÇÃO TERNÁRIA PARA O ENSINO DO CAMPO CONCEITUAL MULTIPLICATIVO}

Em relação a resolução das situações-problema em sala de aula, a Profa. Bia destacou que os alunos avançaram, visto que, anteriormente "a maioria não conseguia respondê-las sem sua intervenção e os erros cometidos não decorriam da interpretação, mas do algoritmo" (Profa. Bia, Diário de campo). Ela começou a acreditar que a intervenção cuidadosa, considerando a leitura da situação sem entonação, análise dos esquemas de resolução dos estudantes e o trabalho com situações variadas contribuiu com o desenvolvimento do raciocínio matemático dos alunos.

As crianças que ainda não têm o domínio da leitura conseguiram compreender as situações com a leitura em voz alta (Profa. Bia, entrevista).

Tal fato confere com os resultados de uma pesquisa apresentada por Curi (2015) em que alunos sem o domínio da leitura conseguiam compreender e resolver as situações-problema usando esquemas próprios como desenhos, agrupamentos e análises. A reflexão da Profa. Bia indicou que ela considerava a aprendizagem de seus alunos como resultado do trabalho pedagógico que estava sendo realizado em sala de aula (PONTE, 2014). E nos disse:

Antes da formação do E-Mult eu me apegava muito a conteúdo, eu tinha que trabalhar certinho, não podia pular nenhum assunto e mesmo que não aprendesse eu passava adiante, pois não podia deixar passar em branco. E, hoje eu vejo diferente, que eu tenho que ter uma base para traçar vários caminhos (Profa. Bia, entrevista).

Assim, ao refletir sobre a sua prática pedagógica e aprendizagem do CCM, a Profa. Bia parece identificar que tinha uma 'ilusão pedagógica' (VERGNAUD, 1983) por acreditar na sequência de conteúdos apresentados nos livros didáticos como a melhor maneira de organização suas aulas.

No último encontro da formação presencial, a Profa. Bia e os demais professores elaboraram oito situações-problema do campo multiplicativo; entre elas, quatro foram classificadas como pertencentes a Relação Ternária. Apresentamos apenas as que são do eixo Comparação Multiplicativa (Figura 10). 
Figura 10 - Situações-problema elaboradas pela Profa. Bia no último encontro da formação presencial

1) A casa de Silbene fica a $3 \mathrm{~km}$ de distância da escola em que trabalha. Alda mora 5 vezes mais distante. Qual a distância da casa de Alda para a escola que Silbene trabalha?

2) João tem 48 anos de idade, seu filho Pedro tem seis vezes menos a sua idade. Qual é a idade de Pedro?

Fonte: Material elaborado na pesquisa (2015).

A situação-problema 1, na Figura 10, é classificada como Relação Ternária, eixo Comparação Multiplicativa, classe Referido desconhecido envolvendo a grandeza do tipo contínuo e a operação de resolução é a multiplicação.

A situação-problema 2, na Figura 10, é classificada como Relação Ternária, eixo Comparação Multiplicativa, classe Referido desconhecido envolvendo a grandeza do tipo discreto, pois a idade foi considerada em anos completos e a operação de resolução é a divisão.

Essas situações apresentam a mesma classe, Referido desconhecido, observamos que a utilização dos termos "vezes mais" e "vezes menos" demonstram uma possível aprendizagem do conceito, pois exigem, respectivamente, as operações de multiplicação e divisão. Além disso, os enunciados assemelhavam-se com as situações trabalhadas na formação. Um possível indicativo de que as situações-problema relacionadas ao CCM, algumas vezes, passaram a ser modelos para elaboração de outras, a serem trabalhadas com os alunos, pois nos estudos de Lima (2016) é possível identificar que antes do processo formativo, quando solicitado para elaborar oito situações multiplicativas, a Profa. Bia elaborou uma situação de Comparação Multiplicativa que buscava o Referido, que trazia a relação de quádruplo de uma medida.

Na Figura 11 apresentamos propostas de solução para essas situações-problema da Comparação Multiplicativa elaboradas pela Profa. Bia. 
Figura 11 - Proposta de resolução para as situações-problema 1 e 2 (Figura 10)

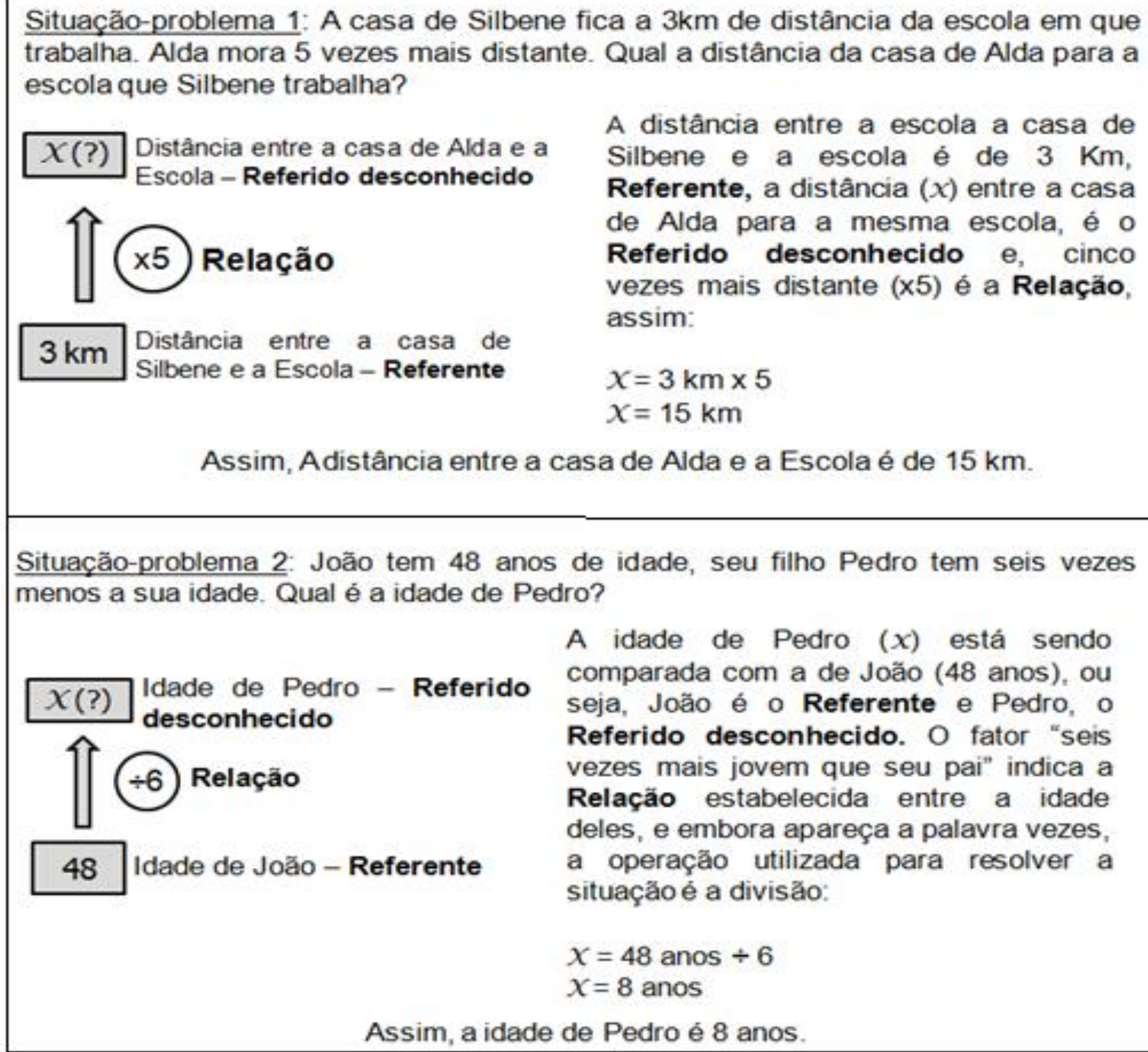

Assim, Adistância entre a casa de Alda e a Escola é de 15 km.

Situação-problema 2: João tem 48 anos de idade, seu filho Pedro tem seis vezes menos a sua idade. Qual é a idade de Pedro?

A distância entre a escola a casa de Silbene e a escola é de $3 \mathrm{Km}$, Referente, a distância $(x)$ entre a casa de Alda para a mesma escola, é o Referido desconhecido e, cinco vezes mais distante $(x 5)$ é a Relaçäo, assim:

$$
\chi=3 \mathrm{~km} \times 5
$$

$$
\begin{aligned}
& \text { A idade de Pedro }(x) \text { está sendo } \\
& \text { comparada com a de Joăo ( } 48 \text { anos), ou } \\
& \text { seja, Joäo é o Referente e Pedro, o } \\
& \text { Referido desconhecido. O fator "seis } \\
& \text { vezes mais jovem que seu pai" indica a } \\
& \text { Relaçăo estabelecida entre a idade } \\
& \text { deles, e embora apareça a palavra vezes, } \\
& \text { a operaçăo utilizada para resolver a } \\
& \text { situaçăo é a divisão: } \\
& x=48 \text { anos }+6 \\
& x=8 \text { anos }
\end{aligned}
$$

Assim, a idade de Pedro é 8 anos.

Fonte: Material elaborado na pesquisa (2015).

A Profa. Bia recorreu à classe Referido desconhecido para elaborar as duas situaçõesproblema da Comparação Multiplicativa. Essa escolha pode estar relacionada com o senso comum, os modelos utilizados em livros didáticos e típicos de operações da tabuada e que, talvez, sejam mais fáceis, pois busca-se o resultado.

\section{CONSIDERAÇÕES}

Os estudos sobre a Relação Ternária, no eixo da Comparação Multiplicativa - Relação, Referente e Referido -, enquanto conhecimento matemático que deve ser aprendido pelo professor, para ajudar os alunos na resolução de situações-problema, contribuiu para a 


\section{O ESTUDO DA RELAÇÃO TERNÁRIA PARA O ENSINO DO CAMPO CONCEITUAL MULTIPLICATIVO}

construção do conhecimento sobre o CCM, enriquecendo o processo formativo e, consequentemente, a docência. A Profa. Bia revelou que a formação possibilitou rever o seu modo de planejar, organizar a aula, fazer as intervenções e avaliar. Essa atitude é oriunda de suas reflexões sobre sua aprendizagem e ensino (Estruturas Multiplicativas).

Inicialmente, a Profa. Bia chegou a dizer que não considerava nenhum ícone, desenho, esquema que era elaborado pelos alunos para responder as atividades que não estivesse de acordo com a resposta que ela esperava. No final da formação, percebeu que esses esquemas eram uma oportunidade para identificar a necessidade de realizar intervenções, pois representam extratos da construção do pensamento e raciocínio matemático do aluno, principalmente, em relação ao campo multiplicativo. Assim, o processo da formação proporcionou indícios de ampliação do seu conhecimento matemático frente às situaçõesproblema do CCM, fortalecendo a sua prática, considerando os seguintes aspectos:

a) o conteúdo da formação (nesse caso, a Relação Ternária - eixo da Comparação Multiplicativa);

b) a formação presencial era organizada tendo a produção escrita de situações-problema como o centro dos estudos sobre as Estruturas Multiplicativas; análise das situações-problema citadas pela pesquisadora e mediadores, nos aspectos teóricos e pedagógicos; e planejamento das atividades de ação pedagógica a serem desenvolvidas em sala de aula;

c) a formação virtual para o aprofundamento dos conceitos - Relação Ternária - com discussão e reflexão dos professores;

d) indícios da ampliação do conhecimento matemático na formação, visto que, ao final da formação, a Profa. Bia conseguiu elaborar situações-problema com diferentes complexidades (multiplicação e divisão); e

e) o movimento entre os encontros de formação presencial e virtual e o encaminhamento de atividades para serem realizadas em sala de aula, com os alunos, e a intervenção realizada pelos professores.

Na trajetória da docência, a Profa. Bia foi percebendo que o trabalho mediado em sala de aula, com a leitura sem entonação, observando os esquemas utilizados pelos alunos e os conceitos que ainda precisavam de interferência para efetivar a aprendizagem, demonstravam ser elementos que potencializavam estratégias de ensino e aprendizagem. Este aspecto corrobora com o depoimento da Profa. Bia quando disse ter se identificado com a ilusão pedagógica [lembrou dos estudos de Vergnaud] por acreditar que o ensino estava baseado na 
sequência das operações fundamentais. Naquele momento da formação estávamos discutindo os conceitos de Vergnaud (1983) sobre o CCM e a reflexão estava relacionada ao rigor das teorias e a transmissão dos conteúdos de forma clara e objetiva.

Nesse sentido, a aprendizagem não foi imediata, pois houve a necessidade de um tempo para iniciar uma possível familiarização com os conceitos (VERGNAUD, 1996). Tal situação ficou evidente visto que os envolvidos na pesquisa (professores e pesquisadores) estavam em processo de construção dos saberes referentes aos CCM e a Relação Ternária.

Assim, o diferencial desta pesquisa foi o de analisar o desenvolvimento de um processo formativo, com professores dos anos iniciais, para compreender na prática os conceitos dessa teoria, conforme os estudos de Vergnaud (1996) para o ensino em sala de aula, considerando que este é um conhecimento do professor para que entenda a construção do conhecimento matemático do estudante.

\section{REFERÊNCIAS}

ALMEIDA, Luana Cerqueira. Solução de situações de comparação multiplicativa e a criatividade matemática. Dissertação. Educação Matemática. Mestrado UESC, Ilhéus, 2017.

BRASIL. MEC/CAPES. Observatório da Educação. Disponível em http://www.capes.gov.br/educacao-basica/observatorio-da-educacao Acesso em 21 dez. 2015. CURI, Edda. Resolução de problemas do campo multiplicativo por crianças de 7 e 8 anos. In: Anais... $4^{\circ}$ Simpósio Internacional de Pesquisa em Educação Matemática. Ilhéus: 2015. IMBERNÓN, Francisco. Formação Permanente do Professor: Novas tendências. São Paulo: Cortez, 2009.

LIMA, Débora Cabral. A formação continuada de professores que ensinam matemática nos anos iniciais e as estruturas multiplicativas. Dissertação. Educação Matemática. Mestrado UESC, Ilhéus, 2016.

LÜDKE, Menga. O Professor, seu saber e sua pesquisa. Revista Educação e Sociedade. Campinas, v.22, n. 74, 2001.

LÜDKE, Menga; ANDRÉ, Marli. Pesquisa em Educação: Abordagens Qualitativas. São Paulo: EPU, 1986.

MAGINA, Sandra Maria Pinto; MERLINI, Vera Lucia; SANTOS, Aparecido dos. A Estrutura Multiplicativa sob a ótica da Teoria dos Campos Conceituais: uma visão do ponto de vista da aprendizagem. In: Anais... $3^{\circ}$ Simpósio Internacional de Pesquisa em Educação Matemática. Fortaleza, 2012.

MAGINA, Sandra Maria Pinto; SANTOS, Aparecido dos; MERLINI, Vera Lucia. O raciocínio de estudantes do Ensino Fundamental na resolução de situações das estruturas multiplicativas. Ciênc. Educ., Bauru, v. 20, n.2, 2014. 
PONTE, João Pedro da. (Org.). Tarefas no ensino e na aprendizagem da Matemática. In: Práticas profissionais dos professores de Matemática. Lisboa: Universidade de Lisboa Instituto de Educação, 2014.

SANTANA, Eurivalda Ribeiro. Estruturas Aditivas: o suporte didático influencia a aprendizagem do estudante? Tese (Educação Matemática/doutorado PUC/SP). São Paulo, 2012.

SANTOS, Aparecido dos. Formação de professores e as estruturas multiplicativas: reflexões teóricas e práticas. 1. Ed. Curitiba: Appris, 2015.

VERGNAUD, Gérard. Multiplicate structures. In: RESH, R.; LANDAU, M. (Orgs.). Acquisitions of mathematics concepts and processes. New York. Academic Press, 1983.

VERGNAUD, Gérard. La théorie des champs conceptuais. Recherches en Didactique des Mathématiques, v. 10, n.23, 133-170, Grenoble: La Pensée Sauvage éditions, 1991.

VERGNAUD, Gérard. A Teoria dos Campos Conceituais. In: BRUN, J. Didáctica das matemáticas. Tradução por Maria José Figueiredo. Lisboa: Instituto Piaget, 1996.

VERGNAUD, Gérard. O que é aprender? In: BITTAR, Marilena. MUNIZ, Cristiano Alberto (Org.). A aprendizagem matemática na perspectiva da teoria dos campos conceituais. Curitiba: Editora CRV, 2009.

VERGNAUD, Gérard. A Criança, a Matemática e a Realidade: Problemas do ensino da matemática na escola elementar. Tradução de Maria Lúcia Faria Moro. Edição revisada. Curitiba: Editora da UFPR, 2014.

\section{NOTAS}

\footnotetext{
${ }^{\text {i }}$ Este artigo é parte da dissertação de mestrado intitulada "A formação continuada de professores que ensinam Matemática nos anos iniciais e as Estruturas Multiplicativas” defendida em 2016 no Programa de Pós-graduação em Educação Matemática (PPGEM-UESC). Essa pesquisa está inserida em um projeto aprovado pelo programa Observatório de Educação (OBEDUC) que fez parte de políticas públicas de fortalecimento da Pós-Graduação em Educação e a Educação Básica, valorizando a parceria entre a Coordenação de Aperfeiçoamento de Pessoal de Nível Superior (CAPES), o Instituto Nacional de Estudos e Pesquisas Educacionais Anísio Teixeira (INEP) e a Secretaria de Educação Continuada, Alfabetização, Diversidade e Inclusão (SECADI) tendo como meta proporcionar a articulação entre pós-graduação, graduação/licenciaturas e Educação Básica, bem como estimular a produção acadêmica e a formação de pós-graduados, em nível de mestrado e doutorado.

ii MAGINA, Sandra Maria Pinto; SANTOS, Aparecido dos; MERLINI, Vera Lúcia. O Raciocínio de estudantes do Ensino Fundamental na resolução de situações das Estruturas Multiplicativas. Ciênc. Educ., Bauru, v. 20, n. 2 , p. 517-533, 2014. Estudado do primeiro ao sexto encontro. SANTOS, Aparecido dos. Formação de professores e as estruturas multiplicativas: reflexões teóricas e práticas. 1. Ed. Curitiba: Appris, 2015. (Capítulo terceiro) estudado do sétimo ao décimo encontro.

iii Aliança produtiva é o movimento construído na universidade e na escola com professores pesquisadores e professores da educação básica como campo colaborativo de aprendizagem e formação, considerando a experiência de cada um (LÜDKE, 2001).
} 